Problems]. Avtomatika i telemekhanika [Automation and Remote Control], 1974, no. 9, pp. 111-118 (in Russian).

3. Vagin V. S., Gropen V. O., Pozdniakova T. A., Budaeva A. A. Mnogokriterial'noe ranzhirovanie ob"ektov metodom etalonov kak instrument optimal'nogo upravleniia. Ustoichivoe razvitie gornykh territorii [Sustainable Development of Mountain Territories], 2010, no 1. pp. 47-55 (in Russian).
4. Keeney R. L., Raiffa H. Decisions with Multiple Objectives: Preferences and Value Tradeoffs. New York, John Wiley \& Sons, Inc., 1976. (Rus. ed. : Keeney R. L., Raiffa H. Priniatie reshenii pri mnogikh kriteriiakh: predpochteniia i zameshcheniia. Moscow, Radio i sviaz', 1981).

5. Rosen V. V. Matematicheskie modeli priniatiia reshenii v ekonomike. [Mathematic decision-making models in economy]. Moscow, Vysshaia shkola, 2002 (in Russian).

\title{
SYSTEMS OF DIFFERENTIAL EQUATIONS ON THE LINE WITH REGULAR SINGULARITIES
}

\section{O. B. Gorbunov ${ }^{1}$, C.-T. Shieh ${ }^{2}$, V. A. Yurko ${ }^{1}$}

\author{
${ }^{1}$ Saratov State University, 83, Astrakhanskaya str., 410012, Saratov, Russia, GorbunovOB@gfm.ru, yurkova@info.sgu.ru \\ ${ }^{2}$ Tamkang University, Taiwan, ctshieh@mail.tku.edu.tw
}

Non-selfadjoint second order differential systems on the line having a non-integrable regular singularity are studied. We construct special fundamental systems of solutions with prescribed analytic and asymptotic properties. Asymptotics of the corresponding Stockes multipliers is established.

Key words: differential systems, singularity, spectral analysis.

\section{INTRODUCTION}

Consider the Dirac system on the line with a regular singularity:

$$
B Y^{\prime}(x)+\left(Q_{0}(x)+Q(x)\right) Y(x)=\lambda Y(x), \quad-\infty<x<+\infty,
$$

where

$$
Y(x)=\left(\begin{array}{l}
y_{1}(x) \\
y_{2}(x)
\end{array}\right), \quad B=\left(\begin{array}{cc}
0 & 1 \\
-1 & 0
\end{array}\right), \quad Q(x)=\left(\begin{array}{cc}
q_{1}(x) & q_{2}(x) \\
q_{2}(x) & -q_{1}(x)
\end{array}\right), \quad Q_{0}(x)=\frac{\mu}{x}\left(\begin{array}{ll}
0 & 1 \\
1 & 0
\end{array}\right),
$$

here $\mu$ is a complex number, $q_{j}(x)$ are complex-valued absolutely continuous functions, and $q_{j}^{\prime}(x) \in L(-\infty,+\infty)$. In this short note we construct special fundamental systems of solutions for system (1) with prescribed analytic and asymptotic properties. Behavior of the corresponding Stockes multipliers is established. These fundamental systems of solutions will be used for studying direct and inverse problems of spectral analysis by the contour integral method and by the method of spectral mappings $[1,2]$.

Differential equations with singularities inside the interval play an important role in various areas of mathematics as well as in applications. Moreover, a wide class of differential equations with turning points can be reduced to equations with singularities. For example, such problems appear in electronics for constructing parameters of heterogeneous electronic lines with desirable technical characteristics $[3,4]$. Boundary value problems with discontinuities in an interior point appear in geophysical models for oscillations of the Earth [5]. The case when a singular point lies at the endpoint of the interval was investigated fairly completely for various classes of differential equations in [6-8] and other works. The presence of singularity inside the interval produces essential qualitative modifications in the investigation (see [9]).

Our plan is the following. In the next section we consider a model Dirac operator with the zero potential $Q(x) \equiv 0$ and without the spectral parameter. It is important that this system is studied in the complex $x$-plane. We construct fundamental matrices for the model system. Using analytic continuations and symmetry we calculate directly the Stockes multipliers for the model system. Then we consider the Dirac system on the real $x$-line with $Q(x) \equiv 0$ and with the complex spectral parameter, and carry over our constructions to this system. In the last section 3 we construct fundamental matrices for system (1) with necessary analytic and asymptotic properties. Asymptotic properties of the Stockes multipliers for system (1) are also established. 


\section{SYSTEMS WITHOUT SPECTRAL PARAMETERS}

Let for definiteness, $\operatorname{Re} \mu>0,1 / 2-\mu \notin \mathbf{N}$. Consider the model Dirac system in the complex $x$-plane:

$$
B Y^{\prime}(x)+Q_{0}(x) Y(x)=Y(x) .
$$

Let $x=r e^{i \varphi}, r>0, \varphi \in(-\pi, \pi], x^{\xi}=\exp (\xi(\ln r+i \varphi))$, and $\Pi_{-}$be the $x$-plane with the cut $x \leqslant 0$. Let numbers $c_{10}, c_{20}$ be such that $c_{10} c_{20}=1$. Then equation (2) has the matrix solution

$$
C(x)=\widehat{C}(x) H(x),
$$

where

$$
\begin{gathered}
H(x)=\left(\begin{array}{cc}
x^{\mu_{1}} & 0 \\
0 & x^{\mu_{2}}
\end{array}\right), \quad \widehat{C}(x)=\sum_{k=0}^{\infty} x^{2 k}\left(\begin{array}{cc}
x c_{1,2 k+1} & c_{2,2 k} \\
-c_{1,2 k} & x c_{2,2 k+1}
\end{array}\right), \\
c_{j, 2 k}=(-1)^{k} \frac{c_{j 0}}{2^{k} k ! \prod_{s=0}^{k-1}\left(2 \mu_{j}+1+2 s\right)}, \quad c_{j, 2 k+1}=(-1)^{k} \frac{c_{j 0}}{2^{k} k ! \prod_{s=0}^{k}\left(2 \mu_{j}+1+2 s\right)},
\end{gathered}
$$

$\mu_{j}=(-1)^{j} \mu, j=1,2$. We agree that if a certain symbol denotes a matrix solution of the system, then the same symbol with one index denotes columns of the matrix, and this symbol with two indeces denotes entries, for example, $C(x)=\left(C_{1}(x), C_{2}(x)\right)=\left(\begin{array}{ll}C_{11}(x) & C_{12}(x) \\ C_{21}(x) & C_{22}(x)\end{array}\right)$.

The functions $\widehat{C}_{k}(x), k=1,2$, are entire in $x$, and the functions $C_{k}(x), k=1,2$ are regular in $\Pi_{-}$. The functions $C_{k}(x), k=1,2$, form the fundamental system of solutions for (2), and $\operatorname{det} C(x) \equiv 1$. Denote

$$
I=\left(\begin{array}{ll}
1 & 0 \\
0 & 1
\end{array}\right), \quad J=\left(\begin{array}{cc}
0 & 1 \\
1 & 0
\end{array}\right), \quad K=\left(\begin{array}{cc}
1 & 0 \\
0 & -1
\end{array}\right), \quad e^{0}(x)=\left(\begin{array}{cc}
i e^{i x} & -i e^{-i x} \\
e^{i x} & e^{-i x}
\end{array}\right) .
$$

Note that the matrix $e^{0}(x)$ is a solution of the system $B Y^{\prime}(x)=Y(x)$.

The matrix Jost-type solution $e(x)=\left(e_{1}(x), e_{2}(x)\right)$ of system (2) is constructed from the following system of integral equations:

$$
e(x)=\frac{1}{d(x)}\left(I+\frac{\mu}{2 x} J\right) e^{0}(x)\left(I-\frac{1}{2} \int_{x}^{\infty} e^{0,-1}(t)(J+\mu B) \frac{\mu}{t^{2}} e(t) d t\right)
$$

where $e^{0,-1}(t)=\left(e^{0}(t)\right)^{-1}, d(x):=\operatorname{det}\left(I-\frac{1}{2} Q_{0}(x)\right)=1-\frac{\mu^{2}}{4 x^{2}}$. One can check that if $e(x)$ is a solution of equation (5), then $e(x)$ satisfies system (2). The following theorem is proved in [10]. Denote $R_{1}=i$, $R_{2}=-i, z_{j}(x)=e^{-R_{j} x} e_{j}(x), z_{j}^{0}(x)=e^{-R_{j} x} e_{j}^{0}(x), j=1,2$.

Theorem 1. Equation (3) has the analytic in $\Pi_{-}$solution $e(x)=\left(e_{1}(x), e_{2}(x)\right)$ such that

1) $\left|z_{1}(x)-z_{1}^{0}(x)\right| \leqslant C /|x|$ for $|x| \geqslant x_{0}$, $\arg x \in\left[-\pi+\delta_{0}, \pi\right]$;

2) $\left|z_{2}(x)-z_{2}^{0}(x)\right| \leqslant C /|x|$ for $|x| \geqslant x_{0}$, arg $x \in\left[-\pi, \pi-\delta_{0}\right]$,

where the constant $C$ depends only on $x_{0}, \delta_{0}, \mu$, and $x_{0} \sin \delta_{0} \geqslant 4 \pi|\mu|(1+|\mu|)$.

The matrix $e(x)$ is a fundamental matrix for system (2), and $\operatorname{det} e(x)=2 i$. For $x \in D_{+}:=$ $=\{z \mid \arg z \in(0, \pi]\}$ the following relations hold

$$
-K e_{2}(-x) \equiv e_{1}(x), \quad K C_{j}(-x) \equiv(-1)^{j} e^{-i \pi \mu_{j}} C_{j}(x), \quad j=1,2 .
$$

In the domain $|\arg x| \leqslant \pi-\delta_{0}$ we have two fundamental matrices; then $e(x)=C(x) \gamma^{0}$ and $C(x)=e(x) \beta^{0}$; the matrices $\gamma^{0}, \beta^{0}$ are called the Stockes multipliers.

Theorem 2. For the Stockes multipliers of system (2) the following relations hold $\operatorname{det} \gamma^{0}=2 i$, $\gamma_{11}^{0}=e^{-i \pi \mu_{1}} \gamma_{12}^{0}, \gamma_{21}^{0}=-e^{-i \pi \mu_{2}} \gamma_{22}^{0}, \gamma_{11}^{0} \gamma_{21}^{0}=(i \cos \pi \mu)^{-1}$. 
Proof. The first assertion follows from the relations $\operatorname{det} e(x)=\operatorname{det} C(x) \operatorname{det} \gamma^{0}$, $\operatorname{det} e(x) \equiv 2 i$, $\operatorname{det} C(x) \equiv 1$. In order to prove the second assertion we rewrite $e(x)=C(x) \gamma^{0}$ in the vector form:

$$
e_{1}(x)=\gamma_{11}^{0} C_{1}(x)+\gamma_{21}^{0} C_{2}(x), \quad e_{2}(x)=\gamma_{12}^{0} C_{1}(x)+\gamma_{22}^{0} C_{2}(x)
$$

Let $x \in D_{+}$. Substututing $-x$ to the second relation and multiplying on $(-K)$, we get $e_{1}(x)=$ $=\gamma_{12}^{0} e^{-i \pi \mu_{1}} C_{1}(x)+\gamma_{22}^{0}\left(-e^{-i \pi \mu_{2}}\right) C_{2}(x)$. Therefore $\gamma_{11}^{0}=e^{-i \pi \mu_{1}} \gamma_{12}^{0}, \quad \gamma_{21}^{0}=-e^{-i \pi \mu_{2}} \gamma_{22}^{0}$. Since $\operatorname{det} \gamma^{0}=\gamma_{11}^{0} \cdot\left(-e^{i \pi \mu_{2}}\right) \gamma_{21}^{0}-e^{i \pi \mu_{1}} \gamma_{11}^{0} \gamma_{21}^{0}$, it follows that $\gamma_{11}^{0} \gamma_{21}^{0}=(i \cos \pi \mu)^{-1}$.

Theorem 2 is proved.

Corollary. The following properties of the Stockes multipliers $\beta^{0}$ hold:

$$
\operatorname{det} \beta^{0}=(2 i)^{-1}, \quad \beta_{11}^{0}=e^{-i \pi \mu_{1}} \beta_{21}^{0}, \quad \beta_{12}^{0}=-e^{-i \pi \mu_{2}} \beta_{22}^{0}, \quad \beta_{21}^{0} \beta_{22}^{0}=(4 i \cos \pi \mu)^{-1} .
$$

Now we consider the system

$$
B Y^{\prime}+Q_{0}(x) Y=\lambda Y
$$

for real $x \neq 0$ and complex $\lambda$. We will use a simple but important property: if $Y(x)$ is a solution of (2), then $Y(\lambda x)$ is a solution of (4).

Denote $C(x, \lambda)=C(x \lambda) H\left(\lambda^{-1}\right), e(x, \lambda)=e(x \lambda)$. Clearly, $C_{j}(x, \lambda)=x^{\mu_{j}} \widehat{C}_{j}(x, \lambda)$, where $\widehat{C}_{j}(x, \lambda)=\widehat{C}_{j}(x \lambda), e_{j}(x, \lambda)=e^{R_{j} \lambda x} z_{j}(x \lambda), j=1,2$. The following theorem is obvious.

Theorem 3. 1) $C(x, \lambda)$ is a fundamental matrix for system (4), $\operatorname{det} C(x, \lambda) \equiv 1, C(x, \lambda)$ is entire in $\lambda$, and $|\widehat{C}(x \lambda)| \leqslant C$ for each $x \lambda$ from a compact set.

2) $e(x, \lambda)$ is a fundamental matrix for system (4), $\operatorname{det} e(x, \lambda) \equiv 2 i$, and $\left|z_{j}(x \lambda)-z_{j}^{0}\right| \leqslant C_{0}|x \lambda|^{-1}$ for $|x \lambda| \geqslant x_{0}, \arg (x \lambda) \in\left[-\pi+\delta_{0}, \pi\right]$ for $j=1, \arg (x \lambda) \in\left[-\pi, \pi-\delta_{0}\right]$ for $j=2$, where $C_{0}$ depends only on $x_{0}, \mu, \delta_{0}$, and $x_{0} \sin \delta_{0} \geqslant 4 \pi|\mu|(1+|\mu|)$.

3) Let $e(x, \lambda)=C(x, \lambda) \gamma^{0}(\lambda)$ and $C(x, \lambda)=e(x, \lambda) \beta^{0}(\lambda)$. Then

$$
\gamma_{j k}^{0}(\lambda)=\lambda^{\mu_{j}} \gamma_{j k}^{0}, \quad \beta_{k j}^{0}(\lambda)=\lambda^{-\mu_{j}} \beta_{k j}^{0}, \quad k, j=1,2 .
$$

\section{SYSTEMS WITH THE SPECTRAL PARAMETER}

Now we consider system (1) and assume that

$$
\int_{|x| \leqslant 1}|x|^{-2 \operatorname{Re} \mu}|Q(x)| d x+\int_{|x| \geqslant 1}|Q(x)| d x<\infty .
$$

In this section we construct fundamental matrices for system (1) and establish properties of their Stockes multipliers. The following assertion is proved by the well-known method (see, for example, [1, 2]).

Theorem 4. System (1) has a fundamental system of solutions $S_{j}(x, \lambda)=x^{\mu_{j}} \widehat{S}_{j}(x, \lambda), j=1,2$, where the functions $\widehat{S}_{j}(x, \lambda)$ are solutions of the integral Volterra equations (5):

$$
\widehat{S}_{j}(x, \lambda)=\widehat{C}_{j}(x, \lambda)+\int_{0}^{x} C(x, \lambda) C^{-1}(t, \lambda)\left(\frac{t}{x}\right)^{\mu_{j}} B Q(t) \widehat{S}_{j}(t, \lambda) d t, \quad j=1,2 .
$$

The functions $S_{j}(x, \lambda)$ are entire in $\lambda$, and $\left|\widehat{S}_{j}(x, \lambda)\right| \leqslant C$ on compact sets.

Let us now construct the Birkhoff-type fundamental system of solutions for system (1). For definiteness, we confine ourselves to the case $x>0$. In section 2 we constructed the solution $e(x, \lambda)$ of equation (4) for $|x \lambda| \geqslant x_{0},|\arg \lambda| \leqslant \pi-\delta_{0}$, where $x_{0}>0, \delta_{0}>0$ are such that $x_{0} \sin \delta_{0} \geqslant 4 \pi|\mu|(1+|\mu|)$. The Stockes multipliers allow one to extend this solution by $e(x, \lambda)=C(x, \lambda) \gamma^{0}(\lambda)$ on $\Pi_{-}$and $x \neq 0$. Denote

$$
F(x \lambda)=\left(\begin{array}{cc}
F_{1}(x \lambda) & 0 \\
0 & F_{2}(x \lambda)
\end{array}\right), \quad F_{j}(x \lambda)= \begin{cases}(x \lambda)^{-\mu} & \text { for }|x \lambda|<2|\mu|, \\
e^{R_{j} \lambda x} & \text { for }|x \lambda| \geqslant 2|\mu| .\end{cases}
$$

Let $U^{0}(x, \lambda)=\left(U_{1}^{0}(x, \lambda), U_{2}^{0}(x, \lambda)\right):=e(x, \lambda) F^{-1}(x \lambda)$. It is easy to check that $\left|U^{0}(x, \lambda)\right| \leqslant C$ for $x>0$, $|\arg \lambda| \leqslant \pi / 2$. The Birkhoff-type solutions $E_{j}(x, \lambda), j=1,2$, of system (1) is constructed from the following systems of integral equations: 
1) for $x \leqslant a_{\lambda}:=2|\mu| /|\lambda|$

$$
\begin{gathered}
E_{1}(x, \lambda)=e_{1}(x, \lambda)+e(x, \lambda)\left(I_{1} \int_{0}^{x} e^{-1}(t, \lambda) B Q(t) E_{1}(t, \lambda) d t-I_{2} \int_{x}^{a_{\lambda}} e^{-1}(t, \lambda) B Q(t) E_{1}(t, \lambda) d t-\right. \\
\left.-\frac{1}{2} I_{2} e^{-1}\left(a_{\lambda}, \lambda\right) Q^{-1}\left(a_{\lambda}, \lambda\right) Q\left(a_{\lambda}\right) E_{1}\left(a_{\lambda}, \lambda\right)\right), \\
E_{2}(x, \lambda)=e_{2}(x, \lambda)+e(x, \lambda) \int_{0}^{x} e^{-1}(t, \lambda) B Q(t) E_{2}(t, \lambda) d t ;
\end{gathered}
$$

2) for $x \geqslant a_{\lambda}$

$$
\begin{aligned}
E_{1}(x, \lambda)= & e_{1}(x, \lambda)-\frac{1}{2} Q^{-1}(x, \lambda) Q(x) E_{1}(x, \lambda)++e(x, \lambda)\left(I_{1} \int_{0}^{a_{\lambda}} e^{-1}(t, \lambda) B Q(t) E_{1}(t, \lambda) d t+\right. \\
+ & \frac{1}{2} I_{1} \int_{a_{\lambda}}^{x} e^{-1}(t, \lambda) L(t, \lambda) E_{1}(t, \lambda) d t-\frac{1}{2} I_{2} \int_{x}^{\infty} e^{-1}(t, \lambda) L(t, \lambda) E_{1}(t, \lambda) d t+ \\
& \left.+\frac{1}{2} I_{1} e^{-1}\left(a_{\lambda}, \lambda\right) Q^{-1}\left(a_{\lambda}, \lambda\right) Q\left(a_{\lambda}\right) E_{1}\left(a_{\lambda}, \lambda\right)\right) \\
E_{2}(x, \lambda)= & e_{2}(x, \lambda)-\frac{1}{2} Q^{-1}(x, \lambda) Q(x) E_{2}(x, \lambda)+e(x, \lambda)\left(\int_{0}^{a_{\lambda}} e^{-1}(t, \lambda) B Q(t) E_{2}(t, \lambda) d t+\right. \\
+ & \left.\frac{1}{2} \int_{a_{\lambda}}^{x} e^{-1}(t, \lambda) L(t, \lambda) E_{2}(t, \lambda) d t+\frac{1}{2} e^{-1}\left(a_{\lambda}, \lambda\right) Q^{-1}\left(a_{\lambda}, \lambda\right) Q\left(a_{\lambda}\right) E_{2}\left(a_{\lambda}, \lambda\right)\right)
\end{aligned}
$$

where $I_{1}=\left(\begin{array}{ll}1 & 0 \\ 0 & 0\end{array}\right), I_{2}=\left(\begin{array}{ll}0 & 0 \\ 0 & 1\end{array}\right), Q(x, \lambda)=Q_{0}(x)-\lambda I$

$$
L(t, \lambda)=\left(Q^{-1}(t, \lambda) Q(t)\right)^{\prime}+Q^{-1}(t, \lambda)(Q(t) B Q(t)+Q(t) B Q(t, \lambda)+Q(t, \lambda) B Q(t)) .
$$

One can check that if $E_{j}(x, \lambda), j=1,2$ are solutions of these systems, then they are solutions of system (1). Denote $U(x, \lambda)=\left(U_{1}(x, \lambda), U_{2}(x, \lambda)\right):=E(x, \lambda) F^{-1}(x \lambda)$, where $E(x, \lambda)=\left(E_{1}(x, \lambda), E_{2}(x, \lambda)\right)$. The following two theorems are proved by similar arguments as in [7].

Theorem 5. Systems (6)-(7) and (8)-(9) have solutions $E_{j}(x, \lambda), j=1,2$ for $x>0$ and $\lambda \in\left\{\lambda:|\lambda| \geqslant \lambda_{0}, \arg \lambda \in(0, \pi / 2]\right\}$, and $\left|U_{j}(x, \lambda)-U_{j}^{0}(x, \lambda)\right| \leqslant M /|\lambda|^{\nu}$, where the constant $M$ depends on $\mu, Q(x), Q^{\prime}(x)$.

Since $E(x, \lambda)$ and $S(x, \lambda)$ are fundamental matrices of system (1), it follows that $E(x, \lambda)=S(x, \lambda) \gamma(\lambda)$ and $S(x, \lambda)=E(x, \lambda) \beta(\lambda)$; the matrices $\gamma(\lambda)$ and $\beta(\lambda)$ are called the Stockes multipliers.

Theorem 6. The following relations hold:

1) $\gamma_{j 2}(\lambda)=\lambda^{\mu_{j}} \gamma_{j 2}^{0}, j=1,2$;

2) $\gamma_{j 1}(\lambda)=\lambda^{\mu_{j}} \gamma_{j 1}^{0}\left(1+O\left(|\lambda|^{-\nu}\right)\right)$ for $|\lambda| \rightarrow \infty, j=1,2$, where $\gamma_{i j}^{0}$ are the Stockes multipliers from $e(x)=C(x) \gamma^{0}$.

Corollary. $\left|\beta_{k j}(\lambda)-\beta_{k j}^{0} \cdot \lambda^{-\mu_{j}}\right| \leqslant C|x \lambda|^{-\nu}, k, j=1,2$.

The results have been obtained in the framework of the national tasks of the Ministry of Education and Science of the Russian Federation (project no. 1.1436.2014K) and by the Russian Foundation for Basic Research (project no. 13-01-00134).

\section{References}

1. Naimark M. A. Linear Differential Operators. New York, Ungar, 1967, pt. I; 1968, pt. II.

2. Yurko V. A. Method of Spectral Mappings in the Inverse Problem Theory. Inverse and Ill-posed Problems Series, Utrecht, VSP, 2002.

3. Litvinenko O. N., Soshnikov V. I. The Theory of

Heterogenious Lines and their Applications in Radio Engineering. Moscow, Radio, 1964 (in Russian).

4. Freiling G., Yurko V. A. Reconstructing parameters of a medium from incomplete spectral information. Results. Math., 1999, vol. 35, iss. 3-4, pp. 228-249. DOI: 10.1007/BF03322815. 
no. 6, pp. 901-928. DOI: 10.1070/SM1995v186n06ABEH

5. Lapwood F. R., Usami T. Free Oscilations of the Earth. Cambridge, Cambridge University Press, 1981.

6. Gasymov M. G. Determination of Sturm-Liouville equation with a singular point from two spectra. Sov. Math. Dokl., 1965, vol. 6, pp. 396-399.

7. Yurko V. A. Inverse problem for differential equations with a singularity. Differ. Equations, 1992, vol. 28, pp. 1100-1107.

8. Yurko V. A. On higher-order differential operators with a regular singularity. Sb. Math., 1995, vol. 186,
000048 .

9. Yurko V. A. Integral transforms connected with differential operators having singularities inside the interval. Integral Transforms and Special Functions, 1997, vol. 5, no. $3-4$, pp. $309-322$

10. Gorbunov O., Shieh C.-T., Yurko V. Spectral analysis of the Dirac system with a singularity in an interior point. arXiv:1410.2020v1 [math.SP], $17 \mathrm{p}$.

УДК 517.984

\title{
Системы диффференциальных уравнений на оси с регулярными особенностями
}

\begin{abstract}
О. Б. Горбунов ${ }^{1}$, Ч.-Т. Шие ${ }^{2}$, В. А. Юрко ${ }^{3}$
${ }^{1}$ Кандидат фризико-математических наук, доцент кафредры математической фризики и вычислительной математики, Саратовский государственный университет имени Н. Г. Чернышевского, GorbunovOB@gfm.ru

${ }^{2}$ Просрессор, Тамканский университет, г. Тайбэй, Тайвань, ctshieh@mail.tku.edu.tw

${ }^{3}$ Доктор фризико-математических наук, просрессор, заведующий кафредрой математической фризики и вычислительной математики, Саратовский государственный университет имени Н. Г. Чернышевского, yurkova@info.sgu.ru

Исследуются несамосопряженные дифрференциальные системы второго порядка на оси с неинтегрируемой регулярной особенностью. Построены специальные фундаментальные системы решений с указанными аналитическими и асимптотическими свойствами. Получена асимптотика соответствующих множителей Стокса.
\end{abstract}

Ключевые слова: дисрфреренциальные системы, сингулярность, спектральный анализ.

Результаты получены в рамках выполнения государственного задания Минобрнауки России (проект № 1.1436.2014K) и при поддержке РФФИ (проект № 13-01-00134).

\section{Библиограсрический список}

1. Наймарк М. А. Линейные дифференциальные операторы. М. : Наука, 1969.

2. Yurko V. A. Method of Spectral Mappings in the Inverse Problem Theory. Inverse and Ill-posed Problems Series. Utrecht: VSP, 2002.

3. Литвиненко О. Н., Сошников В. И. Неоднородные линии и их приложения в радиотехнике. М. : Радио, 1964.

4. Freiling G., Yurko V. A. Reconstructing parameters of a medium from incomplete spectral information // Results. Math. 1999. Vol. 35. P. 228-249.

5. Lapwood F. R., Usami T. Free Oscilations of the Earth. Cambridge : Cambridge University Press, 1981.

6. Гасымов М. Г. Определение уравнения Штурма-
Лиувилля с особенностью по двум спектрам // Докл. AH CССР. 1965. T. 161. C. 274-276.

7. Юрко В. А. Обратная задача для дифференциальных уравнений с особенностью // Дифференц. уравнения. 1992. Т. 28, № 8. С. 1355-1362.

8. Юрко В. А. О дифференциальных операторах высших порядков с регулярной особенностью // Матем. сб. 1995. Т. 186, № 6. С. 133-160.

9. Yurko $V$. A. Integral transforms connected with differential operators having singularities inside the interval // Integral Transforms and Special Functions. 1997. Vol. 5, № 3-4. P. 309-322.

10. Gorbunov O., Shieh C.-T., Yurko V. Spectral analysis of the Dirac system with a singularity in an interior point. arXiv:1410.2020v1 [math.SP]. 17 p.

УДК 517.9

\section{О ДИФФЕРЕНЦИАЛЬНЫХ ОПЕРАТОРАХ И МАТРИЦАХ ВТОРОГО ПОРЯДКА}

\section{А. Ю. Дуплищева}

Аспирантка касредры математических методов исследования операций, Воронежский государственный университет, dupl_ayu@mail.ru

Изучаются дисрференциальные операторы второго порядка. Приводятся условия их обратимости. Основные результаты получены на основе сопоставления исследуемому оператору операторной матрицы второго порядка.

Ключевые слова: дисрфреренциальный оператор, обратимый оператор, ядро оператора, образ оператора. 